\title{
Kinetic and Mechanism of Oxidation of Methylaminopyrazole Formamidine by Alkaline Hexacyanoferrate(III) and the Effect of Divalent Transition Metal Ions
}

\author{
Ahmed Fawzy ${ }^{1,2, ~ *, ~ I s h a q ~ Z a a f a r a n y ~}{ }^{1}$, Naeema Yarkandi ${ }^{1}$, Ameena Al-Bonayan ${ }^{1}$, Zakiya Almallah $^{1}$ \\ ${ }^{1}$ Chemistry Department, Faculty of Applied Science, Umm Al-Qura University, Makkah, Saudi Arabia \\ ${ }^{2}$ Chemistry Department, Faculty of Science, Assiut University, Assiut, Egypt
}

Email address:

afsaad13@yahoo.com (A. Fawzy), iazaafarany@uqu.edu.sa (I. Zaafarany), dr.naeema.y@gmail.com (N. Yarkandi), benayana@hotmail.com (A. Al-Bonayan),zdmallah@uqu.edu.sa (Z. Almallah)

\section{To cite this article:}

Ahmed Fawzy, Ishaq Zaafarany, Naeema Yarkandi, Ameena Al-Bonayan, Zakiya Almallah. Kinetic and Mechanism of Oxidation of Methylaminopyrazole Formamidine by Alkaline Hexacyanoferrate(III) and the Effect of Divalent Transition Metal Ions. Science Journal of Chemistry. Vol. 4, No. 1, 2016, pp. 1-8. doi: 10.11648/j.sjc.20160401.11

\begin{abstract}
In aqueous alkaline medium, the kinetics of oxidation of methylaminopyrazole formamidine (MAPF) by hexacyanoferrate(III) (HCF)has been studied spectrophotometrically under the conditions, MAPF $>>$ HCF at a constant ionic strength of $0.1 \mathrm{~mol} \mathrm{dm}^{-3}$ and at $25^{\circ} \mathrm{C}$. The reaction showed first order dependence on [HCF] while it exhibited fractional-first order kinetics with respect to $[\mathrm{MAPF}]$ and $\left[\mathrm{OH}^{-}\right]$. The oxidation rate increased with increasing ionic strength and dielectric constant of the reaction medium. Addition of small amounts of some divalent transition metal ions accelerates the oxidation rate and the order of catalytic efficiency was: $\mathrm{Cu}(\mathrm{II})>\mathrm{Ni}(\mathrm{II})>\mathrm{Zn}(\mathrm{II})>\mathrm{Co}(\mathrm{II})>\mathrm{Cd}(\mathrm{II})$. The suggested mechanism involves formation of a 1: 1 intermediate complex between $\mathrm{HCF}$ and the deprotonated MAPF species in a pre-equilibrium step. The final oxidation products were identified as methylaminopyrazole, dimethylamine and carbon dioxide. The appropriate rate law was deduced. The reaction constants involved in the mechanism were evaluated. The activation and thermodynamic parameters were determined and discussed.
\end{abstract}

Keywords: Kinetics, Mechanism, Oxidation, Hexacyanoferrate(III), Methylaminopyrazole Formamidine

\section{Introduction}

Oxidation reactions are very important in nature and are regarded as key transformations in organic synthesis. During the last few decades formamidines have achieved commendable importance due to their very broad spectrum of biological activity $[1,2]$. The $N, N$-dialkyl derivatives of formamidines are highly effective acaricides and the most rewarding of these studies resulted in discovery of the acaricide insecticide chlordimeform [3, 4]. The oxidative cleavage of formamidines is quite important, since the $N, N$ dialkyl formamidine group is one of the most versatile protecting groups, especially in biosynthetic applications. Also, methylaminopyrazole was employed as beta-sheet template to investigate its interaction with ferrocenoyldipeptides [5].

Oxidation of organic compounds by hexacyanoferrate(III) as an efficient one-electron oxidant has been a subject of much interest especially in alkaline media [6-17]. The usefulness of HCF may be due to its high stability, water solubility and its moderate reduction potential of $0.45 \mathrm{~V}$, leading to its reduction to $\mathrm{HCF}(\mathrm{II})$, a stable product [18]. In addition, it adds less error to the experimental results, and data can be analyzed meticulously to establish the reaction path.

On the other hand, complexes of metal ions with organic ligands containing $\mathrm{N}, \mathrm{S}$ or $\mathrm{O}$ are well known [13-17]. The presence of heteroatom in such ligands plays a key role when coordinated with transition metal ions. Such complexes exhibit remarkable biological activity against certain microbes, viruses and tumors $[19,20]$.

A literature survey revealed no work has been reported about the kinetics and mechanism of oxidation of methylaminopyrazole formamidine by any oxidant. Hence, the title reaction has been investigated in order to establish the optimum conditions affecting oxidation of MAPF, to check the selectivity of MAPF towards HCF and finally to arrive at a plausible reaction mechanism. 


\section{Experimental}

\subsection{Materials}

All chemicals used throughout the present work were of reagent grade and doubly distilled water was used in all preparations. The solution of MAPF was freshly prepared by dissolving the sample in doubly distilled water. A solution of hexacyanoferrate(III) was prepared by dissolving potassium hexacyanoferrate(III) (BDH) in water and its concentration was ascertained spectrophotometrically. Hexacyanoferrate(II) solution was obtained by dissolving potassium hexacyanoferrate(II) (S. D fine Chem.) in water and standardizing with cerium(IV) solution [21]. Sodium hydroxide, sodium perchlorate and $t$-butyl alcohol were used to vary the alkalinity, ionic strength and dielectric constant in the reaction medium, respectively.

\subsection{Kinetic Measurements}

Kinetic measurements were performed under pseudo-first order conditions where MAPF was present in a large excess over that of HCF. The ionic strength, $I$, of the reaction mixture was adjusted to $0.1 \mathrm{~mol} \mathrm{dm}{ }^{-3}$ using $\mathrm{NaClO}_{4}$ as an inert electrolyte. The reaction temperature $\left(25^{\circ} \mathrm{C}\right)$ was controlled within $\pm 0.1^{\circ} \mathrm{C}$. The progress of HCF reduction was followed by measuring the decay of its absorption spectrophotometrically at $\lambda_{\max }=420 \mathrm{~nm}$, its absorption maximum, where it absorbs to a considerably greater extent than any of the other reactants and products. It was also verified that there is no interference from other reagents at this wavelength. The spectrophotometer was Shimadzu UV-VIS-NIR-3600 double-beam. First order plots of $\ln$ (absorbance) versus time were found to be good straight lines up to at least $80 \%$ of the reaction completion and the pseudofirst order rate constant values were calculated as the gradients of such plots. Average values of at least two independent determinations of the rate constant were taken for the analysis. The rate constants were reproducible to within $4 \%$. A few kinetic runs were carried out after bubbling purified nitrogen and compared with those taken under air, and the results were found to be the same. Thus the dissolved oxygen did not have any effect on the oxidation rate.

The order of reaction with respect to the reactants were determined from the slopes of $\log k_{\text {obs }}$ versus $\log$ (concentration) plots by varying the concentrations of substrate and alkali, in turn, while keeping other conditions constant.

\section{Results}

\subsection{Stoichiometry and Product Identification}

The stoichiometry was determined spectrophotometrically which indicates the consumption of two HCF ions for one molecule of MAPF to yield the oxidation products as shown in the following equation,

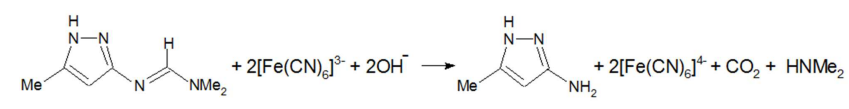

The above stoichiometric equation is consistent with the results of product identification which carried out by spectral and elemental analysis as described elsewhere [22-24].

\subsection{Spectral Changes}

The spectral changes during the oxidation of MAPF by HCF in aqueous alkaline medium are shown in Figure 1. The scanned spectra indicate gradual disappearance of HCF band with time at its absorption maximum, $\lambda=420 \mathrm{~nm}$, as a result of its reduction $\mathrm{HCF}(\mathrm{II})$.

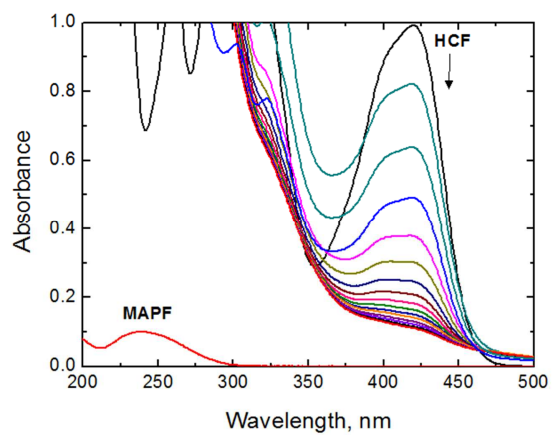

Figure 1. Spectral changes during the oxidation of MAPF by HCF in alkaline medium. $[\mathrm{HCF}]=7.0 \times 10^{-4},[\mathrm{MAPF}]=0.01,\left[\mathrm{OH}^{-}\right]=6.0 \times 10^{-3}$ and $\mathrm{I}=0.1$ mol dm ${ }^{-3}$ at $25^{\circ} \mathrm{C}$.

\subsection{Effect of [HCF]}

HCF concentration was varied in the range of $(3.0-13.0)$ $\mathrm{x} 10^{-4} \mathrm{~mol} \mathrm{\textrm {dm } ^ { - 3 }}$ at constant concentrations of other reagents and constant ionic strength and temperature. The plots of $\ln$ (absorbance) versus time were linear for more than $80 \%$ of the reaction completion. Furthermore, the observed first order rate constant, $k_{\text {obs }}$, was found to be independent of the initial concentration of HCF (Table 1). These results suggest first order dependence of the reaction on [HCF].

\subsection{Effect of [MAPF]}

The reaction rate was measured at different concentrations of the reductant MAPF keeping other reactant concentrations constant. The plot of $k_{\mathrm{obs}}$ versus [MAPF] was found to be linear with a positive intercept (Figure 2) indicating that the reaction order with respect to [MAPF] was found to be less than unity.

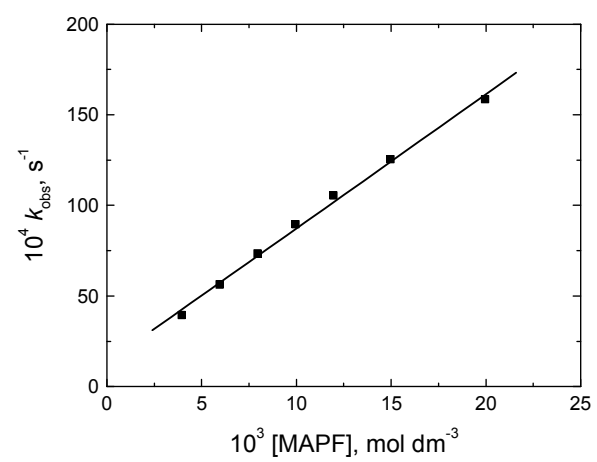

Figure 2. Effect of MAPF concentration on the rate of oxidation of MAPF by $\mathrm{HCF}$ in alkaline medium. $[\mathrm{HCF}]=7.0 \times 10^{-4},[\mathrm{OH}]=6.0 \times 10^{-3}$ and $\mathrm{I}=$ $0.1 \mathrm{~mol} \mathrm{dm}^{-3}$ at $25^{\circ} \mathrm{C}$. 


\subsection{Effect of [OH]}

The effect of $\mathrm{pH}$ on the reaction rate was studied by varying the concentration of $\mathrm{NaOH}$ in the range 2.0 to $14.0 \mathrm{x}$ $10^{-3} \mathrm{~mol} \mathrm{dm}^{-3}$ at constant [MAPF], [HCF], ionic strength and temperature. An increase in alkali concentration was found to accelerate the oxidation rate (Table 1) indicating that the oxidation process was base-catalyzed. A plot of $k_{\mathrm{obs}}$ versus $\left[\mathrm{H}^{+}\right]$was found to be linear with a positive intercept on $k_{\mathrm{obs}}$ axis suggesting that the reaction was fractional-first order as shown in Figure 3.

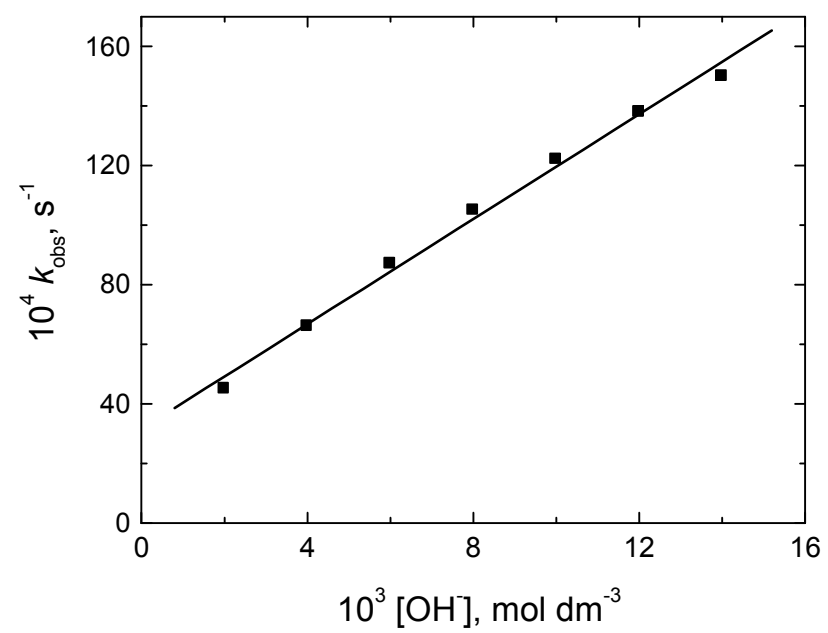

Figure 3. Effect of alkali concentration on the rate of oxidation of MAPF by $H C F$ in alkaline medium. $[H C F]=7.0 \times 10-4,[M A P F]=0.01$ and $I=0.1$ mol dm ${ }^{-3}$ at $25^{\circ} \mathrm{C}$

\subsection{Effect of Ionic Strength and Dielectric Constant of the Reaction Medium}

The ionic strength was varied from 0.1 to $0.4 \mathrm{~mol} \mathrm{dm}^{-3}$ using sodium perchlorate at constant concentrations of MAPF and HCF and at constant $\mathrm{pH}$ and temperature. Increasing the ionic strength increased the reaction rate (Table 1). The Debye-Huckel plot was found to linear with a positive intercept, Figure 4a.

To investigate the effect of the dielectric constant, $D$, of the reaction medium on the rate, the reaction was studied at different solvent compositions of $t$-butyl alcohol and water by varying the alcohol content from 0 to $40 \%(\mathrm{~V} / \mathrm{V})$ in the reaction medium at constant other variables. The results indicate that the reaction rate decreased with decreasing the dielectric constant of the medium, i.e, increasing the alcohol content and the plot of $k_{\mathrm{obs}}$ versus $1 / D$ was found to linear with a negative intercept as illustrated in Figure $4 b$.

Table 1. Effect of variation of [HCF], [MAPF], [OH] and ionic strength (I) on the observed first order rate constant $k_{\text {obs }}$ in the oxidation of MAPF by $H C F$ in alkaline medium at $25^{\circ} \mathrm{C}$.

\begin{tabular}{lllll}
\hline $\begin{array}{l}\mathbf{1 0}[\mathbf{H C F}] \\
(\mathbf{m o l ~ d m}\end{array}$ & $\begin{array}{l}\mathbf{1 0}^{\mathbf{2}}[\mathbf{M A P F}] \\
\left(\mathbf{m o l ~ d m}^{-3}\right)\end{array}$ & $\begin{array}{l}\mathbf{1 0}^{3}\left[\mathbf{O H}^{-}\right] \\
\left(\mathbf{m o l ~ d m}^{-3}\right)\end{array}$ & $\boldsymbol{I}\left(\mathbf{m o l ~ d m} \mathbf{d m}^{-3}\right)$ & $\mathbf{1 0}^{4} \boldsymbol{k}_{\text {obs }}\left(\mathbf{s}^{-1}\right)$ \\
\hline 3.0 & 1.0 & 6.0 & 0.1 & 86.4 \\
5.0 & 1.0 & 6.0 & 0.1 & 89.0 \\
7.0 & 1.0 & 6.0 & 0.1 & 89.2 \\
\hline
\end{tabular}

\begin{tabular}{|c|c|c|c|c|}
\hline $\begin{array}{l}1^{4}[\mathrm{HCF}] \\
\left(\mathrm{mol} \mathrm{dm}^{-3}\right)\end{array}$ & $\begin{array}{l}\begin{array}{l}1^{2} \text { [MAPF] } \\
\left(\mathrm{mol} \mathrm{dm}^{-3}\right)\end{array} \\
\end{array}$ & $\begin{array}{l}\mathbf{1 0}^{3}\left[\mathrm{OH}^{-}\right] \\
\left(\mathbf{m o l ~ d m}^{-3}\right)\end{array}$ & $\left.I(\mathrm{~mol} \mathrm{dm})^{-3}\right)$ & $10^{4} k_{\mathrm{obs}}\left(\mathrm{s}^{-1}\right)$ \\
\hline 9.0 & 1.0 & 6.0 & 0.1 & 90.3 \\
\hline 11.0 & 1.0 & 6.0 & 0.1 & 89.0 \\
\hline 13.0 & 1.0 & 6.0 & 0.1 & 88.5 \\
\hline 15.0 & 1.0 & 6.0 & 0.1 & 92.6 \\
\hline 7.0 & 4.0 & 6.0 & 0.1 & 38.7 \\
\hline 7.0 & 6.0 & 6.0 & 0.1 & 55.9 \\
\hline 7.0 & 8.0 & 6.0 & 0.1 & 73.2 \\
\hline 7.0 & 10.0 & 6.0 & 0.1 & 89.2 \\
\hline 7.0 & 12.0 & 6.0 & 0.1 & 105.0 \\
\hline 7.0 & 15.0 & 6.0 & 0.1 & 125.3 \\
\hline 7.0 & 20.0 & 6.0 & 0.1 & 158.4 \\
\hline 7.0 & 1.0 & 2.0 & 0.1 & 43.1 \\
\hline 7.0 & 1.0 & 4.0 & 0.1 & 66.0 \\
\hline 7.0 & 1.0 & 6.0 & 0.1 & 89.2 \\
\hline 7.0 & 1.0 & 8.0 & 0.1 & 104.7 \\
\hline 7.0 & 1.0 & 10.0 & 0.1 & 121.7 \\
\hline 7.0 & 1.0 & 12.0 & 0.1 & 138.3 \\
\hline 7.0 & 1.0 & 14.0 & 0.1 & 150.1 \\
\hline 7.0 & 1.0 & 6.0 & 0.10 & 89.2 \\
\hline 7.0 & 1.0 & 6.0 & 0.15 & 96.3 \\
\hline 7.0 & 1.0 & 6.0 & 0.20 & 105.2 \\
\hline 7.0 & 1.0 & 6.0 & 0.25 & 112.3 \\
\hline 7.0 & 1.0 & 6.0 & 0.30 & 118.0 \\
\hline 7.0 & 1.0 & 6.0 & 0.35 & 124.9 \\
\hline 7.0 & 1.0 & 6.0 & 0.40 & 131.7 \\
\hline
\end{tabular}

Experimental error $\pm 4 \%$.

\subsection{Effect of Metal Ion Catalysts}

The effect of divalent transition metal ion catalysts were studied by addition of small amounts of the salts of some selected divalent transition metal ions, namely $\mathrm{Co}(\mathrm{II}), \mathrm{Ni}(\mathrm{II})$, $\mathrm{Cu}(\mathrm{II}), \mathrm{Zn}(\mathrm{II})$ and $\mathrm{Cd}(\mathrm{II})$ to the reaction medium at identical concentrations. The results showed that the presence of such ions accelerates the reaction rate. The order of effectiveness $f$ the ions was: $\mathrm{Cu}(\mathrm{II})>\mathrm{Ni}(\mathrm{II})>\mathrm{Zn}(\mathrm{II})>\mathrm{Co}(\mathrm{II})>\mathrm{Cd}(\mathrm{II})$. The plots of $k_{\mathrm{obs}}$ versus the metal ion concentrations were found to be linear with positive intercepts on the $k_{\text {obs }}$ axes as shown in Figure 5.

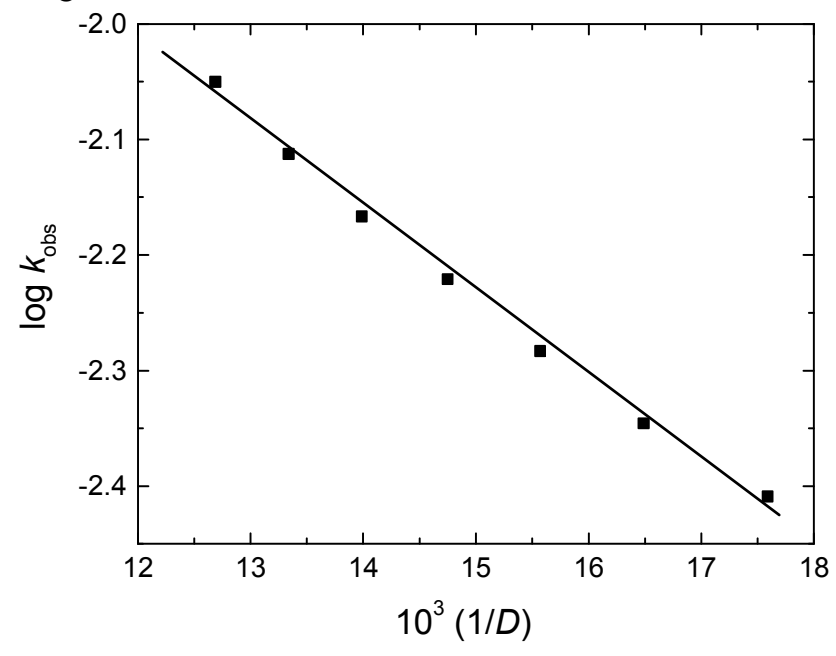

(a) 


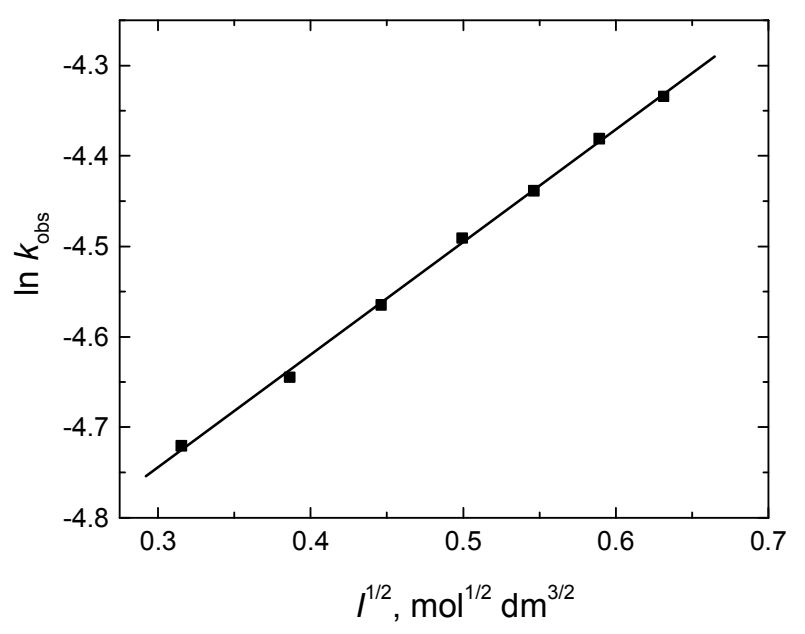

(b)

Figure 4. Effect of: a) ionic strength, and b) dielectric constant on the rate of oxidation of MAPF by $\mathrm{HCF}$ in alkaline medium. $[\mathrm{HCF}]=7.0 \times 10^{-4}$, $[M A P F]=0.01$ and $[\mathrm{OH}]=6.0 \times 10^{-3} \mathrm{~mol} \mathrm{dm}^{-3}$ at $25^{\circ} \mathrm{C}$.

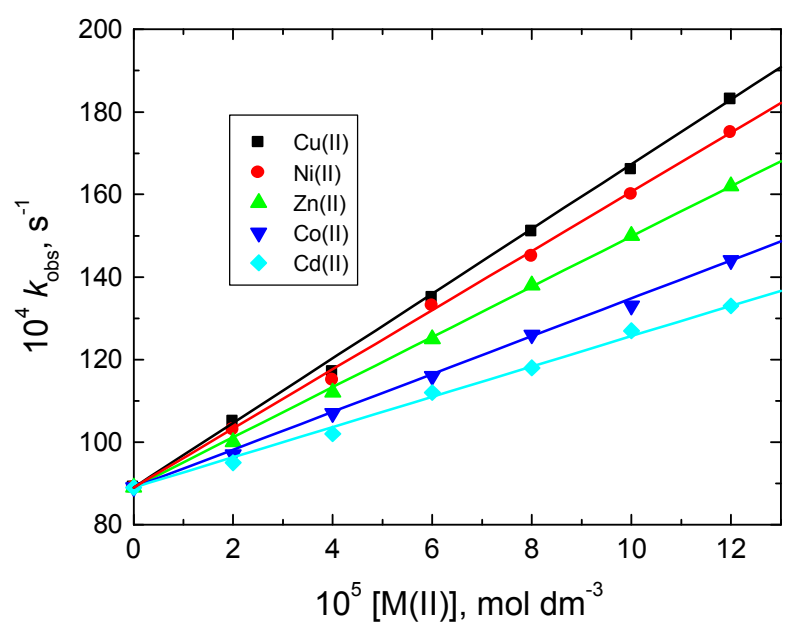

Figure 5. Effect of divalent metal ions on the rate of oxidation of MAPF by $\mathrm{HCF}$ in alkaline medium. $[\mathrm{HCF}]=7.0 \times 10^{-4},[\mathrm{MAPF}]=0.01,\left[\mathrm{OH}^{-}\right]=6.0$ $x 10^{-3}$ and $I=0.1 \mathrm{~mol} \mathrm{dm}^{-3}$ at $25^{\circ} \mathrm{C}$.

\subsection{Effect of Temperature}

The reaction was studied at five temperatures ranging between 20 to $40^{\circ} \mathrm{C}$ with varying both substrate and alkali concentrations keeping other conditions constant. The oxidation rate was found to increase with raising temperature. The activation and thermodynamic parameters were evaluated and were listed in Tables 2 and 3, respectively.

\subsection{Polymerization Test}

The involvement of free radical species in the reaction was assayed by a polymerization test. A known quantity of acrylonitrile monomer was added initially to the reaction mixture in an inert atmosphere, with the result of progressive formation of a white precipitate in the whole reaction mixture indicating presence of free radical during reaction. When the experiment was repeated in the absence of MAPF under similar conditions, the test was negative. This indicates that the reaction was routed through free radical path.

\section{Discussion}

The oxidation MAPF by HCF in alkaline medium had a stoichiometry of 2: 1, i.e., two moles of HCF consumed one mole of MAPF. The reaction exhibited first order dependence with respect to [HCF] and less than unit orders with respect to both $[\mathrm{MAPF}]$ and $\left[\mathrm{OH}^{-}\right]$. The less than unit order in $\left[\mathrm{OH}^{-}\right]$suggests deprotonation of MAPF by the alkali in a pre-equilibrium step to form a more reactive species of the reductant. The rate was not significantly affected by $\mathrm{HCF}(\mathrm{II})$ suggesting absence of any fast equilibrium with the products in the rate-determining step. The latter should be irreversible as is generally the case for one-electron oxidants [25] and the oxidation takes place through generation of a free radical as obtained experimentally. The rate of reaction increased on increasing the ionic strength and dielectric constant of the reaction medium suggesting that the reaction occurs between two similarly charged ions [26, 27].

On the other hand, the less than unit with respect to MAPF concentration may be due to formation of a complex (C) between HCF and deprotonated MAPF species in a preequilibrium step. Complex formation was proved kinetically by the non-zero intercept of the $1 / k_{\mathrm{obs}}$ versus $1 /[\mathrm{MAPF}]$ plot (Figure 6) in favor of possible formation of an intermediate complex between the oxidant and substrate [28]. The formed complex (C) was slowly decomposed in the rate-determining step giving the initial oxidation products as the substrate radical (MAPF') and $\mathrm{HCF}$ (II). The substrate radical reacts with another HCF species in a subsequent fast step to yield an intermediate product, 1, 1dimethyl-2-hydroxyl - 3 - (5- methyl - $1 H$ - pyrazol -3-yl) formamidine. In a further fast step, the intermediate product is hydrolyzed to give the final oxidation products as given in following mechanistic scheme:

$$
\left[\mathrm{Fe}(\mathrm{CN})_{6}\right]^{4}+\underbrace{}_{\mathrm{Me}}
$$

The rate-law equation describing the dependence of the reaction rate on the substrate, oxidant and alkali 
concentrations has been deduced (see Appendix A) to give the following,

$$
\text { Rate }=\frac{k_{1} K K_{1}[\mathrm{MAPF}][\mathrm{HCF}]\left[\mathrm{OH}^{-}\right]}{1+K\left[\mathrm{OH}^{-}\right]+K K_{1}[\mathrm{MAPF}]\left[\mathrm{OH}^{-}\right]}
$$

Under pseudo-first order condition,

$$
\text { Rate }=\frac{-d[\mathrm{HCF}]}{d t}=k_{\mathrm{obs}}[\mathrm{HCF}]
$$

Comparing Eqs. (1) and (2), the following equation is obtained,

$$
k_{\mathrm{U}}=\frac{k_{1} K K_{1}[\mathrm{MAPF}]\left[\mathrm{OH}^{-}\right]}{1+K\left[\mathrm{OH}^{-}\right]+K K_{1}[\mathrm{MAPF}]\left[\mathrm{OH}^{-}\right]}
$$

Equation (3) can be verified by rearranging to Eqs. (4) and (5),

$$
\begin{aligned}
& \frac{1}{k_{\mathrm{U}}}=\left(\frac{1}{k_{1} K K_{1}\left[\mathrm{OH}^{-}\right]}+\frac{1}{k_{1} K_{1}}\right) \frac{1}{[\mathrm{MAPF}]}+\frac{1}{k_{1}} \\
& \frac{1}{k_{\mathrm{U}}}=\left(\frac{1}{k_{1} K K_{1}[\mathrm{MAPF}]}\right) \frac{1}{\left[\mathrm{OH}^{-}\right]}+\frac{1}{k_{1} K_{1}[\mathrm{MAPF}]}+\frac{1}{k_{1}}
\end{aligned}
$$

Equations (4) and (5) required that plots of $1 / k_{\mathrm{obs}}$ versus $1 /[\mathrm{MAPF}]$ at constant $\left[\mathrm{OH}^{-}\right]$, and $1 / k_{\mathrm{obs}}$ versus $1 /\left[\mathrm{OH}^{-}\right]$at constant $[\mathrm{MAPF}]$ to be linear with positive intercepts and are found to be so as shown in Figures 6 and 7, respectively. The values of the rate constant of the slow step $\left(k_{1}\right)$ at different temperatures obtained as reciprocal of the intercepts of $1 / k_{\mathrm{obs}}$ versus $1 /[\mathrm{MAPF}]$ plots along with the activation parameters of $k_{1}$ which calculated from the Eyring plot (Figure 8a) and Arrhenius plot (Figure 8b) and are listed in Table 2. Values of the equilibrium constants associated with the mechanistic scheme $\left(K\right.$ and $\left.K_{1}\right)$ at different temperatures are also calculated from the slopes and intercepts of such plots and are also inserted in Table 3. The thermodynamic parameters of $K$ and $K_{1}$ are evaluated from van't Hoff plot (Figure 10) and are inserted in Table 3.

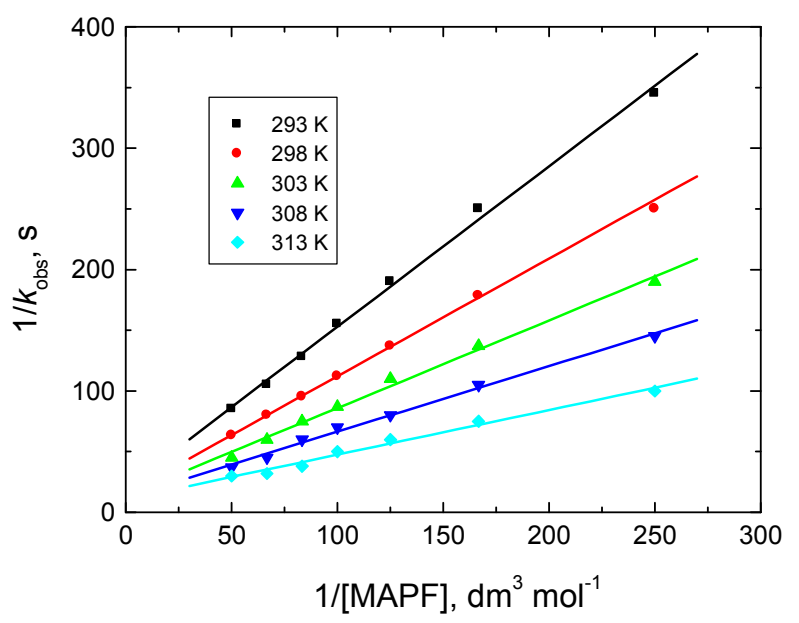

Figure 6. Plots of $1 / k_{\text {obs }}$ versus $1 /[M A P F]$ for the oxidation of MAPF by $\mathrm{HCF}$ in alkaline medium at different temperatures. $[\mathrm{HCF}]=7.0 \times 10^{-4},[\mathrm{OH}]$ $=6.0 \times 10^{-3}$ and $I=0.1 \mathrm{~mol} \mathrm{dm}^{-3}$.

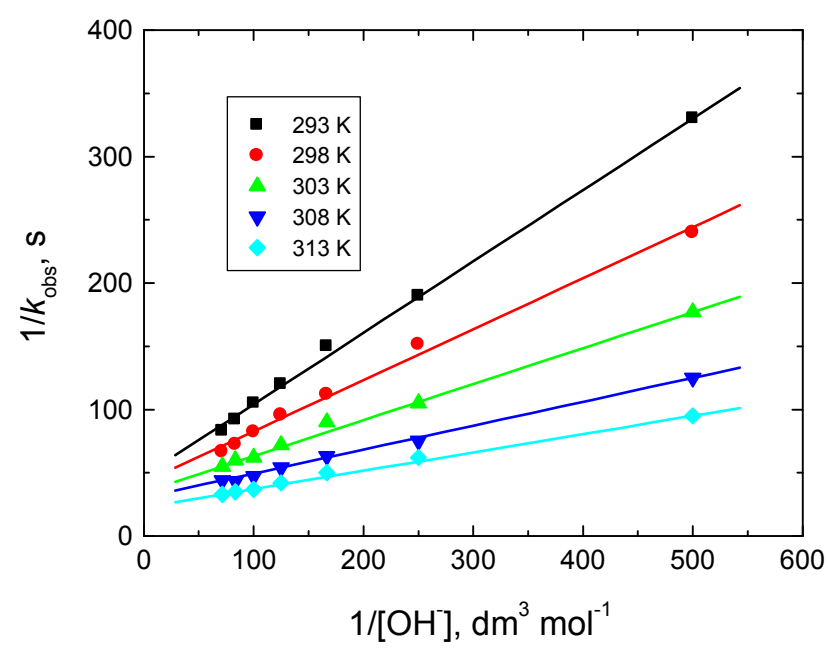

Figure 7. Plots of $1 / k_{\text {obs }}$ versus $1 /\left[\mathrm{OH}^{-}\right]$for the oxidation of MAPF by $\mathrm{HCF}$ in alkaline medium at different temperatures. $[\mathrm{HCF}]=7.0 \times 10^{-4},[\mathrm{MAPF}]=$ 0.01 and $I=0.1 \mathrm{~mol} \mathrm{dm}^{-3}$.

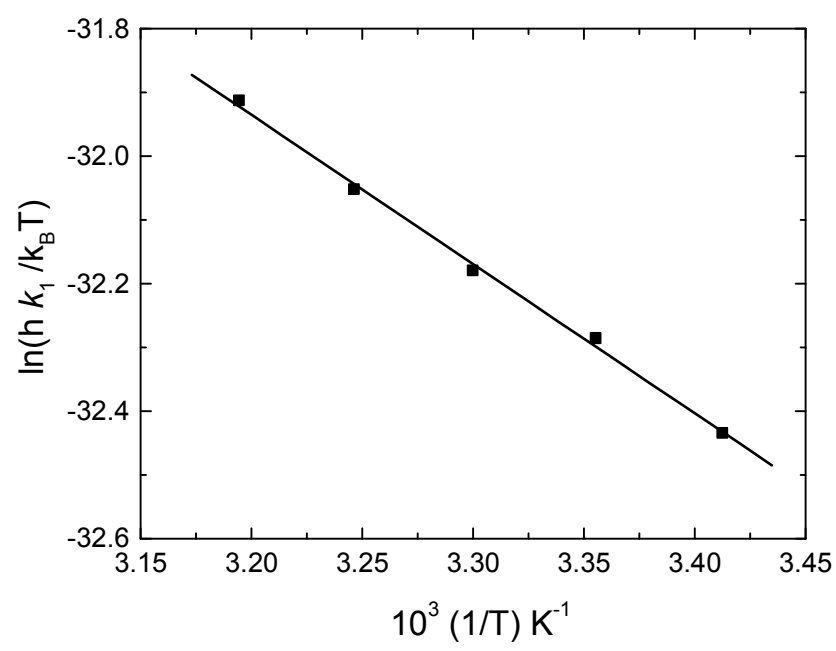

(a)

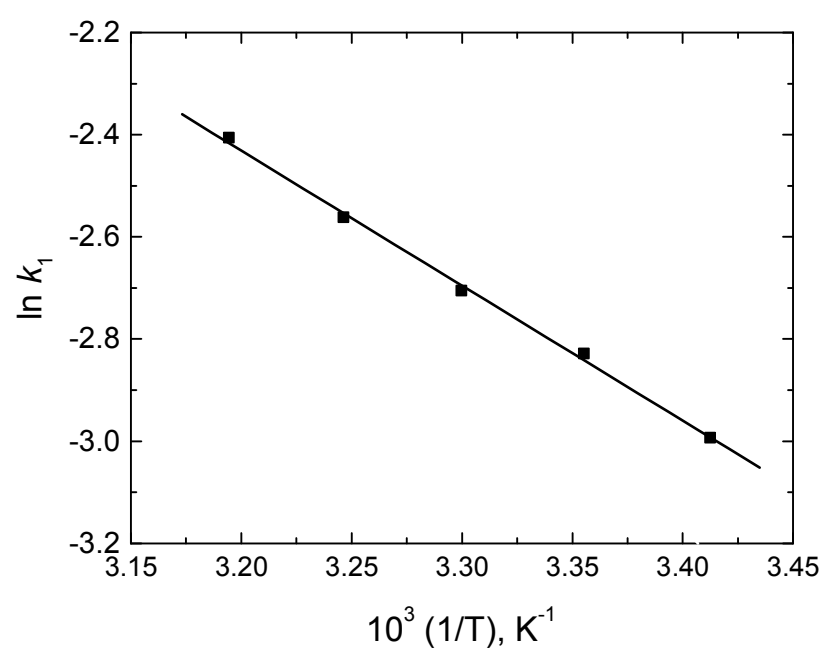

(b)

Figure 8. a) Eyring plot, and b) Arrhenius plot of the second order rate constant, $k_{1}$, in the oxidation of MAPF by HCF in alkaline medium. [HCF] $=7.0 \times 10^{-4},[M A P F]=0.01,\left[\mathrm{OH}^{-}\right]=6.0 \times 10^{-3}$ and $I=0.1 \mathrm{~mol} \mathrm{dm}^{-3}$. 


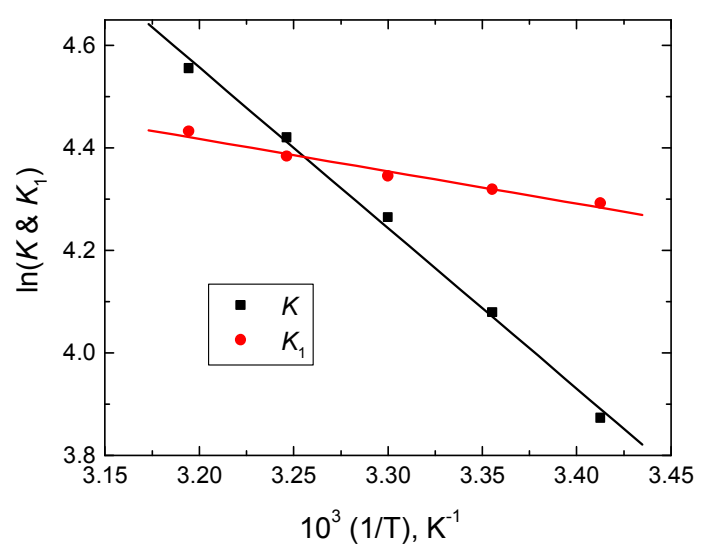

Figure 9. Van'T Hoff plots of $K$ and $K$ in the oxidation of MAPF by HCF in alkaline medium. $[\mathrm{HCF}]=7.0 \times 10^{-4},[\mathrm{MAPF}]=0.01,[\mathrm{OH}]=6.0 \times 10^{-3}$ and $I=0.1 \mathrm{~mol} \mathrm{dm}^{-3}$.

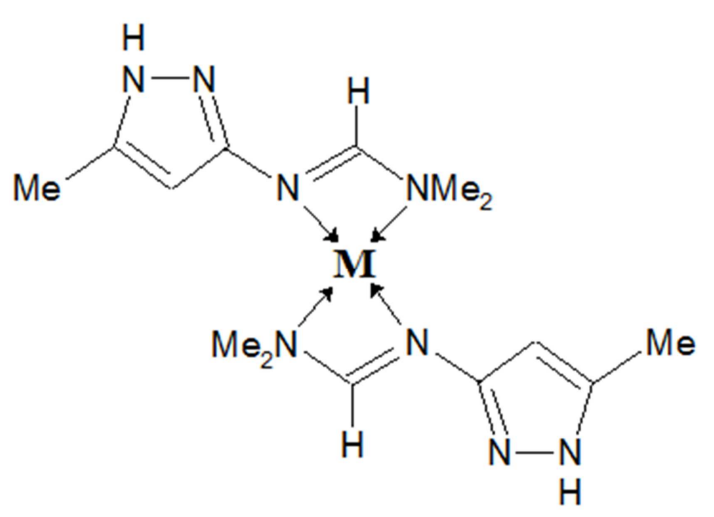

Figure 10. Suggested structure of MAPF complexes with divalent transition metal ions, where $M$ denotes the metal ion.

Table 2. Values of the rate constant of the slow step $\left(k_{l}\right)$ and its associated activation parameters in the oxidation of MAPF by HCF in alkaline medium.

\begin{tabular}{|c|c|c|c|c|c|c|c|c|c|}
\hline \multirow{2}{*}{$\begin{array}{l}\text { Rate } \\
\text { Constant }\left(\mathrm{s}^{-1}\right)\end{array}$} & \multicolumn{5}{|c|}{ Temperature (K) } & \multicolumn{4}{|c|}{ Activation parameters } \\
\hline & 293 & 298 & 303 & 308 & 313 & $\Delta S^{\ddagger}\left(\mathrm{Jmol}^{-1} \mathrm{~K}^{-1}\right)$ & $\Delta H^{\ddagger}\left(\mathrm{kJ} \mathrm{mol}^{-1}\right)$ & $\Delta G^{\ddagger}{ }_{298}\left(\mathrm{~kJ} \mathrm{~mol}^{-1}\right)$ & $E_{\mathrm{a}}^{\ddagger}\left(\mathrm{kJ} \mathrm{mol}^{-1}\right)$ \\
\hline $10^{2} k_{1}$ & 5.01 & 5.93 & 6.67 & 7.71 & 9.10 & -203.69 & 19.45 & 80.15 & 21.95 \\
\hline
\end{tabular}

Experimental error $= \pm 4 \%$

Table 3. Values of the equilibrium constants $\left(K_{1}\right.$ and $\left.K_{2}\right)$ and their thermodynamic quantities in the oxidation of MAPF by HCF in alkaline medium.

\begin{tabular}{|c|c|c|c|c|c|c|c|c|}
\hline \multirow{2}{*}{$\begin{array}{l}\text { Equilibrium } \\
\text { Constant }\left(\mathrm{dm}^{3} \mathrm{~mol}^{-1}\right)\end{array}$} & \multicolumn{5}{|c|}{ Temperature (K) } & \multicolumn{3}{|c|}{ Thermodynamic parameters } \\
\hline & 293 & 298 & 303 & 308 & 313 & $\Delta H^{o}\left(\mathrm{~kJ} \mathrm{~mol}^{-1}\right)$ & $\Delta G_{298}^{o}\left(\mathrm{~kJ} \mathrm{~mol}^{-1}\right)$ & $\Delta S^{o}\left(\mathrm{~J} \mathrm{~mol}^{-1} \mathrm{~K}^{-1}\right)$ \\
\hline$K$ & 48.19 & 59.48 & 71.43 & 83.50 & 94.91 & 26.02 & -10.12 & 121.28 \\
\hline$K_{1}$ & 73.11 & 74.89 & 77.01 & 80.52 & 84.52 & 5.28 & -10.69 & 53.59 \\
\hline
\end{tabular}

Experimental error $\pm 5 \%$

Inspection of the acceleration of the oxidation rate by divalent transition metal ions, it has been reported [32-35] that the catalytic effect of metal ions may be due to bridging that facilitates electron transfer in redox systems, whereas Sheppard and Wahl [36] have interpreted catalytic effect in terms of complex formation. The suggested [37] structures of the complexes of formamidine derivatives with divalent transition metal ions are illustrated in Figure 10. The complexation of such bidentate ligands such as MAPF produced metallo-organic complexes with 1: 2 ratio (metal: ligand). It was also reported [38] that metal complexes can be more active than the free ligands, and can exhibit bioactivities that are not shown by the free ligands.

\section{Conclusion}

The kinetics of oxidation of methylaminopyrazole formamidine by alkaline hexacyanoferrate(III) has been studied. The suggested mechanism involves formation of a 1: 1 intermediate complex between HCF and the deprotonated MAPF species in a pre-equilibrium step. The final oxidation products were identified as methylaminopyrazole, dimethylamine and carbon dioxide. Addition of small amounts of some divalent transition metal ions accelerates the oxidation rate and the order of catalytic efficiency was: $\mathrm{Cu}(\mathrm{II})>\mathrm{Ni}(\mathrm{II})>\mathrm{Zn}(\mathrm{II})>\mathrm{Co}(\mathrm{II})>\mathrm{Cd}(\mathrm{II})$.

\section{Appendix A}

Derivation of the Rate Law Expression:

According to the proposed mechanistic Scheme,

$$
\begin{gathered}
\text { Rate }=\frac{-d[\mathrm{HCF}]}{d t}=k_{1}[\mathrm{C}] \\
K=\frac{\left[\mathrm{MAPF}^{-}\right]}{\left[\mathrm{MAPF}^{-}\left[\mathrm{OH}^{-}\right]\right.},\left[\mathrm{MAPF}^{-}\right]=K[\mathrm{MAPF}]\left[\mathrm{OH}^{-}\right]
\end{gathered}
$$

and

$$
\begin{gathered}
K_{1}=\frac{[\mathrm{C}]}{\left[\mathrm{MAPF}^{-}\right][\mathrm{HCF}]}, \\
{[\mathrm{C}]=K_{1}\left[\mathrm{MAPF}^{-}\right][\mathrm{HCF}]=K K_{1}[\mathrm{MAPF}][\mathrm{HCF}]\left[\mathrm{OH}^{-}\right]}
\end{gathered}
$$

Substituting Eq. (A3) into Eq. (A1) leads to,

$$
\text { Rate }=k_{1} K K_{1}[\mathrm{MAPF}][\mathrm{HCF}]\left[\mathrm{OH}^{-}\right]
$$

The total concentration of MAPF is given by,

$$
[\mathrm{MAPF}]_{\mathrm{T}}=[\mathrm{MAPF}]_{\mathrm{F}}+\left[\mathrm{MAPF}^{-}\right]+[\mathrm{C}]
$$

where ' $\mathrm{T}$ ' and ' $\mathrm{F}$ ' stand for total and free concentrations.

Substituting Eqs. (A2) and (A3) into Eq. (A5) and 
rearrangement gives,

$$
\begin{gathered}
{\left[\mathrm{MAPF}_{\mathrm{T}}=[\mathrm{MAPF}]_{\mathrm{F}}+K[\mathrm{MAPF}]\left[\mathrm{OH}^{-}\right]+\right.} \\
K K_{1}[\mathrm{MAPF}][\mathrm{HCF}]\left[\mathrm{OH}^{-}\right] \\
{[\mathrm{MAPF}]_{\mathrm{T}}=[\mathrm{MAPF}]_{\mathrm{F}}\left(1+K\left[\mathrm{OH}^{-}\right]+K K_{1}[\mathrm{HCF}]\left[\mathrm{OH}^{-}\right]\right)}
\end{gathered}
$$

Therefore,

$$
[\mathrm{MAPF}]_{\mathrm{F}}=\frac{[\mathrm{MAPF}]_{\mathrm{T}}}{1+K\left[\mathrm{OH}^{-}\right]+K K_{1}[\mathrm{HCF}]\left[\mathrm{OH}^{-}\right]}
$$

In view of low $[\mathrm{HCF}]$, the third denominator term $K K_{1}[\mathrm{HCF}][\mathrm{OH}]$ in the above equation can be neglected. Therefore, Eq. (A8) can be simplified to the following,

$$
[\mathrm{MAPF}]_{\mathrm{F}}=\frac{\left[\mathrm{MAPF}_{\mathrm{T}}\right.}{1+K\left[\mathrm{OH}^{-}\right]}
$$

Also,

$$
[\mathrm{HCF}]_{\mathrm{T}}=[\mathrm{HCF}]_{\mathrm{F}}+\left[\mathrm{C}_{1}\right]
$$

Substituting Eq. (A3) into Eq. (A10),

$$
\begin{aligned}
{[\mathrm{HCF}]_{\mathrm{T}} } & =[\mathrm{HCF}]_{\mathrm{F}}\left(1+K K_{1}[\mathrm{ATF}]\left[\mathrm{OH}^{-}\right]\right) \\
{[\mathrm{HCF}]_{\mathrm{F}} } & =\frac{[\mathrm{HCF}]_{\mathrm{T}}}{1+K K_{1}[\mathrm{MAPF}]\left[\mathrm{OH}^{-}\right]}
\end{aligned}
$$

Regarding to the concentration of $\mathrm{OH}^{-}$,

$$
\left[\mathrm{OH}^{-}\right]_{\mathrm{F}}=\left[\mathrm{OH}^{-}\right]_{\mathrm{T}}
$$

Substituting Eqs. (A9), (A12) and (A13) into Eq. (A4) (and omitting ' $\mathrm{T}$ ' and ' $\mathrm{F}$ ' subscripts) leads to,

$$
\text { Rate }=\frac{k_{1} K K_{1}[\mathrm{MAPF}][\mathrm{HCF}]\left[\mathrm{OH}^{-}\right]}{\left(1+K\left[\mathrm{OH}^{-}\right]\right)\left(1+K K_{1}[\mathrm{MAPF}]\left[\mathrm{OH}^{-}\right]\right)}
$$

Under pseudo-first order condition, the rate-law can be expressed by Eq. (A15),

$$
\text { Rate }=\frac{-d[\mathrm{HCF}]}{d t}=k_{\mathrm{obs}}[\mathrm{HCF}]
$$

Comparing Eqs. (A14) and (A15), the following relationship is obtained,

$$
\begin{gathered}
k_{\mathrm{U}}=\frac{k_{1} K K_{1}[\mathrm{MAPF}]\left[\mathrm{OH}^{-}\right]}{\left(1+K\left[\mathrm{OH}^{-}\right]\right)\left(1+K K_{1}[\mathrm{MAPF}]\left[\mathrm{OH}^{-}\right]\right)} \\
k_{\mathrm{U}}=\frac{k_{1} K K_{1}[\mathrm{MAPF}]\left[\mathrm{OH}^{-}\right]}{1+K\left[\mathrm{OH}^{-}\right]+K K_{1}[\mathrm{MAPF}]\left[\mathrm{OH}^{-}\right]+K^{2} K_{1}[\mathrm{MAPF}]\left[\mathrm{OH}^{-}\right]^{2}}
\end{gathered}
$$

The term $K^{2} K_{1}[\mathrm{MAPF}]\left[\mathrm{OH}^{-}\right]^{2}$ in the denominator of Eq. (A17) is negligibly small compared to unity in view of the low concentration of ATF used. Therefore Eq. (A17) can be written as,

$$
k_{\mathrm{U}}=\frac{k_{1} K K_{1}[\mathrm{MAPF}]\left[\mathrm{OH}^{-}\right]}{1+K\left[\mathrm{OH}^{-}\right]+K K_{1}[\mathrm{MAPF}]\left[\mathrm{OH}^{-}\right]}
$$

and with rearrangement, the following equations are obtained,

$$
\begin{aligned}
& \frac{1}{k_{\mathrm{U}}}=\left(\frac{1}{k_{1} K K_{1}\left[\mathrm{OH}^{-}\right]}+\frac{1}{k_{1} K_{1}}\right) \frac{1}{[\mathrm{MAPF}]}+\frac{1}{k_{1}} \\
& \frac{1}{k_{\mathrm{U}}}=\left(\frac{1}{k_{1} K K_{1}[\mathrm{MAPF}]}\right) \frac{1}{\left[\mathrm{OH}^{-}\right]}+\frac{1}{k_{1} K_{1}[\mathrm{MAPF}]}+\frac{1}{k_{1}}
\end{aligned}
$$

\section{References}

[1] Leung VSK, Chan TYK, Yeung VTF (1999) Ami-traz poisining in humans, Clinical Toxicol. 37: 513-514.

[2] Nakayama A, Sukekawa M, Eguchi Y (1997) Stereochemistry and active conformation of a novel insecticide Acetamiprid. Pesticide Sci. 51: 157-164.

[3] Beeman RW, Matsumura F (1973) Chlordimeform: a pesticide acting upon amine regulatory mechanisms. Nature. 242: 273274.

[4] Aziz AA, Knowles CO (1973) Inhibition of monoamine oxidase by the pesticides chlordimeform and related compounds. Nature 242: 417-418.

[5] Saweczko P (2001) Interaction of ferrocenoyl-dipeptides with 3-aminopyrazole derivatives: beta-sheet models: A synthetic, spectroscopic, structural, and electrochemical study. Inorg. Chem. 40: 4409-4419.

[6] Kelson EP, Phengsy PP (2000) Kinetic study of 2-propanol and benzyl alcohol oxidation by alkaline hexacyanoferrate(III) catalysed by a terpyridyl ruthenium complex. Int. J. Chem. Kinet. 32: 760-770.

[7] Vovk AI, Muraveva IV, Kukhar VP, Baklan VF (2000) Kinetics of oxidation of vitamin B1 and its Oacyl analogs with ferricyanide. A mechanistic model of thiamin-binding protein. Russ. J. Gen. Chem. 70: 1108-1112.

[8] Speakman PT, Waters WA (1955) Kinetic features of the oxidation of aldehydes, ketones and nitroparaffins with alkaline ferricyanide. J. Chem. Soc. 40-50.

[9] Jose TP, Nandibewoor ST, Tuwar SM (2006) Kinetics and mechanism of oxidation of vanillin by hexacyanoferrate(III) in aqueous alkaline medium. J. Solution Chem. 35: 51-62.

[10] Singh VN, Singh MP, Saxena BBL (1970) Kinetics and mechanism of alkaline ferricyanide oxidation of acetone and ethyl methyl ketone. Indian J. Chem. 8: 529-532.

[11] Leal JM, Garcia B, Domingo PL (1998) Outer-sphere hexacyanoferrate(III) oxidation of organic substrates. Coord. Chem. Rev. 173: 79-131.

[12] Jose TP, Angadi MA, Salunke MS, Tuwar SM (2008) Oxidative study of gabapentin by alkaline hexacyanoferrate(III) in room temperature in presence of catalytic amount of Ru(III). A mechanistic approach. J. Mol. Struct. 892: 121-124. 
[13] Sharanabasamma K, Angadi MA, Salunke MS, Tuwar SM (2009) Osmium(VIII) catalysed oxidative cleavage of pyrrolidine ring in L-proline by hexacyanoferrate(III) in alkaline media. Ind. Eng. Chem. Res. 48: 10381-10386.

[14] Goel A, Sharma S (2010) Mechanistic study of the oxidation of L-phenylalanine by hexacyanoferrate (III) catalyzed by iridium(III) in aqueous alkaline medium, Transition Met. Chem. 35: 549-554.

[15] Devra V, Yadav MB (2012) Kinetics and mechanism of osmium(VIII) catalyzed oxidation of valine by hexacyanoferrate in alkaline medium, Rassian J. Chem. 5: 67-73.

[16] Upadhyay SK, MC agrawal (1977) Kinetics of Os (VIII)catalyzed alkaline hexacyanoferrate (III) oxidation of some $\alpha$ amino acids in presence of excess of ferricyanide, Ind. J. Chem., 15A: 709-712;

[17] Jose TP, Nandibewoor ST, Tuwar SM (2006) Osmium(VIII) catalyzed oxidation of a sulfur containing amino acid - A kinetic and mechanistic Approach. J. Sulfur Chem., 27: 25-36.

[18] Farokhi SA, Nandibewoor ST (2003) Kinetic, mechanistic and spectral studies for the oxidation of sulfanilic acid by alkaline hexacyanoferrate(III). Tetrahedron 59: 7595-7601.

[19] Padhye S, Kaufman GB (1985) Transition metal complexes of semicarbazones and thiosemicarbazones. Coord. Chem. Rev. 63: 127-160.

[20] Asiri AM, Khan SA (2010) Palladium(II) complexes of NS donor ligands derived from steroidal thiosemicarbazones as antibacterial agents. Molecules 15: 4784-4791.

[21] Jeffery GH, Bassett J, Mendham J, Denney RC (1996) Text Book of Quantitative Chemical Analysis, 5th ed.; ELBS Longman: Essex, pp. 384.

[22] Fawzy A, Shaaban MR (2014) Kinetic and mechanistic investigations on the oxidation of N'-heteroaryl unsymmetrical formamidines by permanganate in aqueous alkaline medium. Transition Met. Chem. 39: 379-386.

[23] Vogel AI (1973) Text book of practical organic chemistry including quantitative organic analysis, 3rd edn, $332 \mathrm{pp}$. ELBS, Longman.

[24] Feigl F (1975) Spot tests in organic analysis, 195 pp. Elsevier, New York.

[25] Leal JM, Domingo PL, Garcla B, Ibeas S (1993) Alkali metal ion catalysis of the oxidation of L-ascorbic acid by hexacyanoferrate(III) in strongly acidic media. J. Chem. Soc. Faraday Trans. 89: 3571-3577.

[26] Frost AA, Person RG (1973) Kinetics and mechanism, 147 pp. Wiley Eastern, New Delhi.

[27] Amis ES (1966) Solvent effect on reaction rates and mechanism, pp. 28, Academic Press, New York.

[28] Michaelis L, Menten ML (1913) The kinetics of invertase action. Biochem. Z. 49: 333-369.

[29] Hicks KW, Toppen DL, Linck RG (1972) Inner-sphere electron-transfer reactions of vanadium (II) with azidoamine complexes of cobalt(III). Inorg. Chem. 11 (1972) 310-315.

[30] Sutin N (1968) Free energies, barriers, and reactivity patterns in oxidation-reduction reactions. Acc. Chem. Res. 1: 225-231.

[31] Freeman F (1981) Permanganate ion oxidations. 13. Soluble manganese (IV) species in the oxidation of 2, 4(1H,3H)pyrimidinediones (uracils). J. Am. Chem. Soc. 103: 11541158.

[32] Meier DJ, Garner CS (1952) The kinetics of the europium (II)-europium (III) exchange reaction. J. Phys. Chem. 56: 853-857.

[33] Duke FR, Parchen RF (1956) The kinetics of the Ce(IV)Ce(III) exchange reaction in perchloric acid. J. Am. Chem. Soc. 78: 1540-1543.

[34] Taube H, Myers H, Rich RL (1953) The mechanism of electron transfer in solution. J. Am. Chem. Soc. 75: 41184119 .

[35] Taube H, Myer, H (1954) Evidence for bridged activated complex for electron transfer re- action. J. Am. Chem. Soc. 76: 2103-2111.

[36] SheppardJC, Wahl AC (1957) Kinetics of the manganatepermanganate exchange reaction. J. Am. Chem. Soc. 79: $1020-1024$

[37] Abdel-Zaher AE (2015) Synthesis of benzoazolyl-N, Ndimethylformamidines: complexation and biological activity, Eur. Int. J. Sci. Technol. 4: 88-99.

[38] Sala R, Bokka AK, Kethavath BKN, Gollapalli NR (2012) Effect of dielectric constant of medium on chemical speciation of L-histidine complexes of $\mathrm{Co}(\mathrm{II}), \mathrm{Ni}(\mathrm{II})$ and $\mathrm{Cu}(\mathrm{II})$. Bull. Chem. Soc. Ethiopia 26: 227-238. 